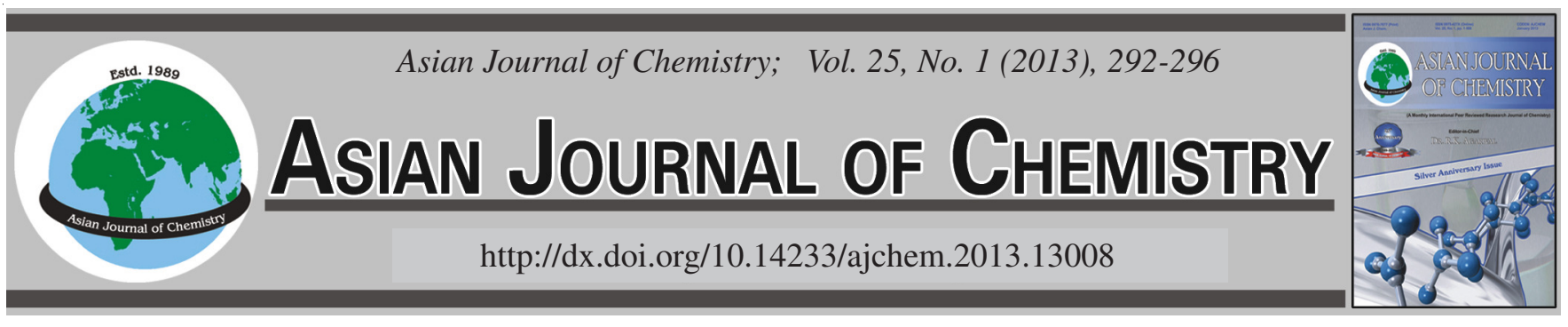

\title{
Effect of Organic Matter on Adsorption and Persistence of Thiram Fungicide in Different Soils
}

\author{
Ritesh Kumar Srivastava ${ }^{1, *}$, BriJesh K. Singh ${ }^{2}$ and Dinesh Mani ${ }^{1}$
}

${ }^{1}$ Department of Chemistry, Sheila Dhar Institute of Soil Science, University of Allahabad, Allahabad-211 002, India

${ }^{2}$ Department of Chemistry, Moti Lal Nehru National Institute of Technology, Allahabad-211 004, India

*Corresponding author: E-mail: dr.dinesh.au@gmail.com

(Received: 3 November 2011;

Accepted: 23 July 2012)

AJC-11865

\begin{abstract}
The Freundlich equation provides a good fit $\left(\mathrm{r}^{2}>0.99\right)$ for the adsorption data on thiram in all the soils. The Freundlich constant $(\mathrm{K})$ value for thiram in Farm Yard Manure (FYM) treated soils were more than in corresponding untreated soils. Thiram showed 'L' type isotherm curve $(1 / \mathrm{n}<1)$ indicated non-linear relationship between the thiram concentration and adsorption. The negative magnitude of Gibbs free energy $(\Delta \mathrm{G})$ indicate that the adsorption was exothermic and spontaneity process. The persistence of thiram indicated a close correspondence to the $\left(r^{2}>0.92\right)$ first order exponential degradation kinetics in the soils and mainly influenced by soil organic matter. The half-life $\left(T_{1 / 2}\right)$ value of thiram was highest for alluvial soil followed by sandy loam and black soils.
\end{abstract}

Key Words: Adsorption, Persistence, Thiram, Half-life, Farm Yard Manure.

\section{INTRODUCTION}

Thiram [bis(dimethyl thiocarbamoyl)disulfide] is a dimethyl dithiocarbamate compound used as a fungicide to prevent crop damage in the field and to protect harvest crops from deterioration in storage or transport. Thiram is also used as a seed protectant and to protect fruits, vegetables, ornamental and turf crop from a variety of fungal disease ${ }^{1-3}$. Pesticide adsorption refers to the bonding of the chemical to sites on soils mineral or organic surfaces and must be considered when calculating fungicide application rates. The adsorption of fungicide is the most important factor controlling mobility and rate of degradation ${ }^{4}$. Adsorption of pesticide in soil depends not only on the properties of the compound but also on the characteristics of soil ${ }^{5}$. Several edaphic factors such as the clay content, type of clay, organic matter, $\mathrm{pH}$ etc., determine the degree of retention of pesticide, but organic matter of soil is the most important factor in the adsorption of pesticide ${ }^{6,7}$. Addition of farm yard manure (FYM) is likely to influence these processes operating in soil. The persistence of thiram depends upon many factors like soil $\mathrm{pH}$, soil salinity, soil organic matter, soil moisture, soil temperature and soil type. Therefore, the present investigation was undertaken to study the adsorption and persistence of thiram influenced by organic matter in texturally different soils.

\section{EXPERIMENTAL}

Sample collection and standardization: Three soil viz. an alluvial, sandy loam and black soils collected from Ganga river basin (India) were air dried and ground to pass through 2 $\mathrm{mm}$ sieve. These soils were kept in desiccators to avoid contact with moisture. Physio-chemical properties (Table-1) like cation exchange capacity (CEC) determined by neutral $1 \mathrm{~N}$ ammonium acetate solution, organic carbon (OC) by chromic acid digestion method, $\mathrm{pH}$ using digital $\mathrm{pH}$ meter in soil water (1:2.5) suspension. Silt, clay were separated by the pipette method and fine sand by decantation ${ }^{8}$. Farm yard manure (FYM) was used as a source of organic matter at rate of $25 \mathrm{~g} \mathrm{ha}^{-1}$.

Technical grade thiram fungicide (purity $>99 \%$ ) was obtained from $\mathrm{M} / \mathrm{s}$ Indofil Chemical (Bombay) India used for the present study. The chemical formula, structure and several properties of this fungicide is indicated below (Fig. 1).

TABLE-1

PHYSICO-CHEMICAL PROPERTY OF THE INVESTIGATED SOILS, INDIA

\begin{tabular}{|c|c|c|c|c|c|c|c|c|}
\hline \multirow{2}{*}{ S. No. } & \multirow{2}{*}{ Soils } & \multicolumn{3}{|c|}{ Mechanical composition } & \multirow{2}{*}{$\mathrm{pH}$} & \multirow{2}{*}{$\begin{array}{c}\text { Organic } \\
\text { carbon }(\%)\end{array}$} & \multirow{2}{*}{$\begin{array}{c}\text { Organic } \\
\text { matter }(\%)\end{array}$} & \multirow{2}{*}{$\begin{array}{c}\mathrm{CEC} \\
{\left[\mathrm{C}\left(\mathrm{p}^{+}\right) \mathrm{mol} \mathrm{kg} \mathrm{kg}^{-1}\right]}\end{array}$} \\
\hline & & Sand (\%) & Silt (\%) & Clay $(\%)$ & & & & \\
\hline 1 & Alluvial soil & 57.2 & 23.8 & 19.0 & 6.2 & 0.23 & 0.39 & 19 \\
\hline 2 & Sandy loam soil & 64.5 & 17.3 & 18.2 & 7.8 & 0.47 & 0.81 & 25 \\
\hline 3 & Black soil & 51.4 & 24.2 & 24.4 & 7.4 & 0.57 & 0.98 & 28 \\
\hline
\end{tabular}


<smiles>CN(C)C(=S)SSC(=S)N(C)C</smiles>

Fig. 1 Chemical structure of thiram

Molecular formula: $\mathrm{C}_{6} \mathrm{H}_{12} \mathrm{~N}_{2} \mathrm{~S}_{4}$, molecular weight: 240.4, other names: Arasan, Thylate, Thiramad; m.p.: $155-156^{\circ} \mathrm{C}$; vapour pressure: $2.3 \mathrm{~m} \mathrm{~Pa}\left(25^{\circ} \mathrm{C}\right)$; solubility at room temperature: $18 \mathrm{mg} \mathrm{L}^{-1}$ (water); $80 \mathrm{~g} \mathrm{~L}^{-1}$ (acetone); $230 \mathrm{~g} \mathrm{~L}^{-1}$ (chloroform); $10 \mathrm{~g} \mathrm{~L}^{-1}$ (ethanol); acute $\mathrm{LD}_{50}$ dose $780 \mathrm{mg} / \mathrm{kg}$ (oralwhite rats); leaching potential: medium; toxicity category: Grade III $^{9}$. Where, the $\mathrm{LD}_{50}$ is the lethal dose of a substance required to kill half of the exposed test animals based on the body weight of the animal.

Sample preparation: For adsorption stock solutions of the thiram were prepared in $0.5 \mathrm{~N}$ sodium hydroxide. Concentration of the working solution used for adsorption studies were $25,50,75$ and $100 \mu \mathrm{g} / \mathrm{mL}$. $1 \mathrm{~g}$ air-dried soil was taken in four of the five test tubes. In all the tubes $10 \mathrm{~mL}$ of the working solution was added. The fifth tube, which did not contain soil, was used as a reference. The tubes were shaken for different time intervals $(0.50,0.75,1.0,1.5,2.0,2.50,3.0,5.0$ and 8.0 h). The equilibrium time was found to 2 h (Fig. 2) and was used in the adsorption studies. Thereafter tubes were taken out and centrifuged for $20 \mathrm{~min}$ at $1000 \mathrm{rpm} .5 \mathrm{~mL}$ of aliquot from each tube was taken out and filtered. The single experiment comprised of one duplicate and one reference for one concentration of thiram for a single soil. Similar experiments were conducted with other natural (untreated) soils and soils with farm yard manure contents at four concentrations. The supernatants collected for adsorption were analyzed by colorimetric method at $420 \mathrm{~nm}$ using cuprous chloride reagent ${ }^{10}$.

For persistence $100 \mathrm{~g}$ of well sieved soils were taken in petridishes, $20 \mathrm{~mL}$ of standard solution $(100 \mu \mathrm{g} / \mathrm{mL})$ of thiram were applied to the soils under laboratory condition. Experiments were arranged to duplicate for thiram fungicide. In another set of treatment farm yard manure $(0.25,0.5$ and $1 \%)$ was used as a source of organic matter. The analysis of thiram remaining in untreated and treated (farm yard manure) soils was carried out of $0,3,6$ and 9 days.

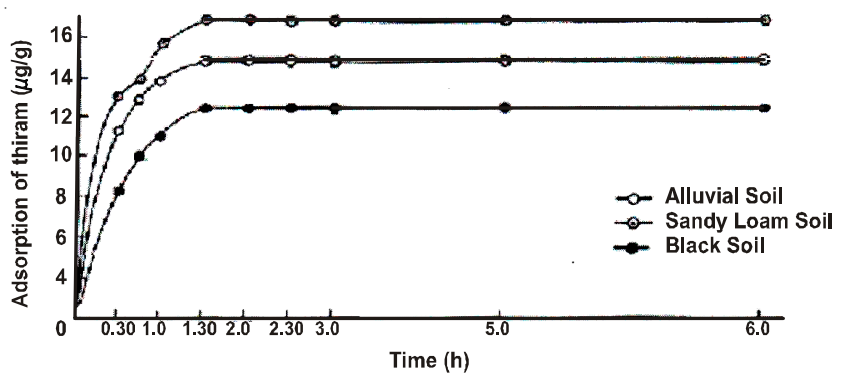

Fig. 2. Adsorption of thiram with equilibration time (h)

Procedure: Two methods were used to analyze the thiram fungicides, a titrimetric and a colorimetric. The titrimetric method, commonly known as "carbon disulfide evolution method" was used to estimate a higher amount of thiram. The colorimetric method was used for the estimation of comparatively lower doses by using a cuprous chloride reagent ${ }^{10}$. Lead acetate solution $(30 \mathrm{~mL})$, was added to the first absorption tubes attached to the distillation apparatus, and $25 \mathrm{~mL}$ of methanolic potassium hydroxide in the second absorber and $5 \mathrm{~mL}$ of methanolic potassium hydroxide in each of the bubblers. Water was allowed to flow through the condenser. The sample was put into the digestion flask. Dropping funnel and air bleed was assembled to add $20 \mathrm{~mL}$ tetra sodium EDTA solution through funnel. Absorption train was connected to a controlled vacuum supply so that approximately three bubbles of air per second or $50 \mathrm{~mL} / \mathrm{min}$ could pass through the system. Sample was well dispersed by swirling the flask gently for about $1 \mathrm{~min}$ and then through dropping funnel $50 \mathrm{~mL}$ boiling $\mathrm{H}_{2} \mathrm{SO}_{4}$ (4 $\mathrm{N}$ aqueous) was quickly added and flask was immediately heated with a naked flame. Brisk rate of reflux was maintained until the sample was fully decomposed ( $c$ a. 25-30 min were required) and then condenser cooling water was stopped for 2-3 min. During this period the condenser and the first absorber were flushed with steam to remove any entrapped carbon disulfide. The burner was removed and the absorption chain was disconnected. The contents of the methanolic potassium hydroxide absorber and bubblers were washed. Two drops of phenolphthalein indicator were added and neutralized with acetic acid with continuous stirring by glass rod and solution was titrated with iodine using starch indicator. The amount of the thiram fungicide was calculated.

\section{Method of calculation:}

$$
\text { [Thiram }(\%)=24.00 \times \mathrm{t} \times \mathrm{n} / \mathrm{w} \text { ] }
$$

where, $[1 \mathrm{~mL}$ of $0.1 \mathrm{~N}$ iodine $=0.024 \mathrm{~g}$ of thiram $], \mathrm{t}=$ titration reading, $\mathrm{n}=$ exact normality of iodine solution and $\mathrm{w}=$ weight of sample.

The quantity of fungicides adsorbed was calculated from the difference between initial concentration and concentration present in the equilibrium solution using the following equation $^{11}$.

$$
\mathrm{A}=(\mathrm{Ci}-\mathrm{Ce}) \mathrm{v} / \mathrm{m}
$$

where, $\mathrm{A}$ is the amount adsorbed ( $\mu \mathrm{g} \mathrm{g}^{-1}$ of soil), $\mathrm{Ci}$ and $\mathrm{Ce}$ are initial and equilibrium concentration $\left(\mu \mathrm{g} \mathrm{mL}^{-1}\right) \mathrm{v}$ is the solution volume $(\mathrm{mL})$ and $\mathrm{m}$ is weight of soil $(\mathrm{g})$.

The adsorption data was fitted as per following Freundlich adsorption equation

$$
\mathrm{X} / \mathrm{m}=\mathrm{K} \cdot \mathrm{Ce} \mathrm{e}^{1 / \mathrm{n}}
$$

where, $\mathrm{x} / \mathrm{m}$ - quantity of fungicides adsorbed per unit weight of soil $\left(\mu \mathrm{g} \mathrm{g}^{-1}\right)$, Ce - equilibrium concentration $\left(\mu \mathrm{g} \mathrm{mL} \mathrm{L}^{-1}\right) . \mathrm{K}$ and $\mathrm{n}$ are empirical constants.

The constants were calculated from the linearized form the Freundlich equation. $\log (\mathrm{x} / \mathrm{m})=\log (\mathrm{K})+1 / \mathrm{n} \log (\mathrm{Ce})$. The constants $\log \mathrm{K}$ and $1 / \mathrm{n}$ is representing the intercept and slopes of isotherms respectively. The statistical average of the distribution coefficient $\left(\mathrm{K}_{\mathrm{d}}\right)$ for each soil was calculated from following equation ${ }^{12}$.

$$
\mathrm{K}_{\mathrm{d}}=\frac{\Sigma\left(\mathrm{x} / \mathrm{m} \mathrm{C}_{\mathrm{e}}\right)}{\Sigma\left(\mathrm{C}_{\mathrm{e}}\right)^{2}}
$$

where, $\Sigma$ indicates the summation of the values.

The normalized sorption coefficient for organic carbon $\left(\mathrm{K}_{\mathrm{oc}}\right)$ was calculated by following formula ${ }^{13}$.

$$
\mathrm{K}_{\mathrm{oc}}=\frac{\mathrm{K}_{\mathrm{d}} \times 100}{\% \text { of organic carbon }}
$$


The normalized sorption coefficient for clay content $\left(\mathrm{K}_{\mathrm{c}}\right)$ was calculated by following equation ${ }^{14}$.

$$
\mathrm{K}_{\mathrm{c}}=\frac{\mathrm{K} \times 100}{\text { clay content }(\%)}
$$

The change in the Gibb's free energy for adsorption was calculated using the following equation ${ }^{15}$.

$$
\Delta \mathrm{G}^{\mathrm{o}}=-\mathrm{RT} \ln (\mathrm{K})
$$

where, $\Delta \mathrm{G}^{\mathrm{o}}$ - Gibb's free energy change $\left(\mathrm{KJ} \mathrm{mol}^{-1}\right)$, R-Gas constant $\left(8.314 \mathrm{~J} \mathrm{~mol}^{-1} \mathrm{~K}^{-1}\right), \mathrm{T}$ - absolute temperature (Kelvin).

In the persistence studies, the amount of pesticide residues that remained at different intervals were fitted to first order exponential decay equation which is as follows:

$$
\mathrm{C}_{\mathrm{t}}=\mathrm{Co} \mathrm{e}^{-\mathrm{kt}}
$$

where, $\mathrm{C}_{\mathrm{t}}$ - the concentration after time, $\mathrm{t}(\mathrm{d})$, Co - initial concentration and $\mathrm{k}$ - rate constant $\left(\mathrm{day}^{-1}\right)$.

The half life was computed using following equation:

$$
\mathrm{T}_{1 / 2}=[0.693 / \mathrm{K}]
$$

\section{RESULTS AND DISCUSSION}

The adsorption of thiram by soils increases with solution concentration. This suggests that adsorption site were not saturated at concentration used. The adsorption of thiram in different soil in each soil is as a function of organic carbon content. The thiram in different soil increases in the order: alluvial soil < sandy loam soil < black soil, which is also the order of increasing of organic carbon content in this soil. This increased adsorption of thiram must be considered when the chemical used in organic matter rich soil. Valverde-Garcia et al..$^{16}$ also established the role of organic molecules in soils. Filipe et $a l .{ }^{17}$ observed that the thiram adsorption increased with increasing initial concentration onto humic acid.

The adsorption of thiram followed a regular increases with increasing equilibrium concentration (Figs. 3 and 4). The adsorption isotherms were concentration dependent. The adsorption isotherms of thiram in soils were L type of the Giles classification ${ }^{18}$. Such adsorptions have been observed by other workers for adsorption of fungicide on different soil ${ }^{17,19}$. The isotherms indicate that greater amount of thiram was adsorbed in the order of black soil > sandy loam soil > alluvial soil. The higher adsorption on black soil may be due to relatively more organic matter content and neutral soil $\mathrm{pH}$ as compared to other soils ${ }^{20}$.

Addition of organic matter by farm yard manure did not change the pattern of adsorption but the quantity adsorbed at each concentration increased as compared to untreated soil (Fig. 4). In treated soil maximum adsorption occurred in black

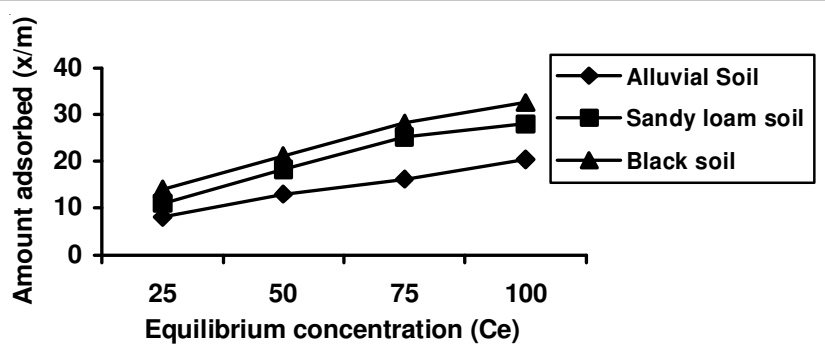

Fig. 3. Adsorption isotherm of thiram on untreated (natural) soils

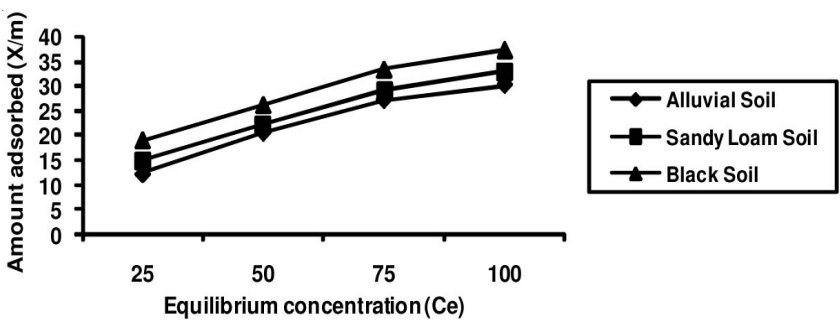

Fig. 4. Adsorption isotherms of thiram on treated (FYM) soils

soil followed by sandy loam and alluvial soil. This suggests that the organic matter, clay content plays important role in adsorption of thiram is further controlled by soil $\mathrm{pH}$ and type of clay ${ }^{21,22}$. Though in the farm yard manure treated soils there was difference in the magnitude of adsorption, the shape of adsorption isotherms remained same ${ }^{23}$. Chowdhury et al. ${ }^{24}$ reported that the soil oragnic matter and $\mathrm{pH}$ may affect pesticide adsorption.

The adsorption data fitted well to Freundlich equation as indicated by straight line relationship between $\log \mathrm{x} / \mathrm{m}$ and $\log C_{e}$ for soils, where slope and intercept provides values of $1 / \mathrm{n}$ and $\mathrm{K}$ respectively. ' $\mathrm{K}$ ' is the measure of the strength of adsorption while $1 / \mathrm{n}$ indicates the degree of linearity between solution equilibrium concentration and adsorption. The Freundlich constants are reported in Tables 2 and 3. The coefficient of determination $r^{2}>0.99$ for all isotherms indicating a good fit of the data to the Freundlich equation. The Freundlich constant $(\mathrm{K})$ values for thiram in farm yard manure treated soil were greater than those in corresponding untreated soils which indicate that organic matter is most important factor in adsorption $^{25}$. The Freundlich constant $(\mathrm{K})$ values for untreated soil ranged from (2.061-1.006) as compared to (4.205-1.586) in treated (farm yard manure) soil. Even after farm yard manure treatment the highest $(\mathrm{K})$ was found black soil > sandy loam soil $>$ alluvial soil, similarly in untreated soil. The $1 / \mathrm{n}$ values for untreated soils $(0.685-0.606)$ is more than $(0.655-0.479)$ treated soils. The increase in $(1 / n)$ implies the stronger binding

\begin{tabular}{|c|c|c|c|}
\hline Soils & Regression equation & Determination coefficient & Gibb's free energy $\Delta \mathrm{G}\left(\mathrm{KJmol}^{-1}\right)$ \\
\hline \multicolumn{4}{|c|}{ Untreated (natural) soils } \\
\hline Alluvial & $\log (x / m)=0.0026+0.653 \log (\mathrm{Ce})$ & 0.99 & -0.0148 \\
\hline Sandy loam & $\log (x / m)=0.1051+0.684 \log (\mathrm{Ce})$ & 0.99 & -0.5977 \\
\hline Black & $\log (x / m)=0.3140+0.606 \log (\mathrm{Ce})$ & 0.99 & -1.7856 \\
\hline \multicolumn{4}{|c|}{ Treated (soil containing FYM) } \\
\hline Alluvial & $\log (x / m)=0.2002+0.654 \log (\mathrm{Ce})$ & 0.99 & -1.1385 \\
\hline Black & $\log (x / m)=0.6238+0.478 \log (\mathrm{Ce})$ & 0.99 & -3.5474 \\
\hline
\end{tabular}
of thiram to the inorganic fraction for untreated soils. Similar

TABLE-2

REGRESSION EQUATION FOR LINEARIZED FORM OF FREUNDLICH EQUATION 
TABLE-3

ADSORPTION KINETICS OF THIRAM IN SOILS

\begin{tabular}{lccccc|ccccc}
\hline \multirow{2}{*}{ Soils } & \multicolumn{4}{c}{ Untreated (Natural) soil } & \multicolumn{5}{c}{ Treated (Soil containing FYM) } \\
\cline { 2 - 12 } & $\mathrm{K}$ & $1 / \mathrm{n}$ & $\mathrm{K}_{\mathrm{d}}$ & $\mathrm{K}_{\mathrm{oc}}$ & $\mathrm{K}_{\mathrm{c}}$ & $\mathrm{K}$ & $1 / \mathrm{n}$ & $\mathrm{K}_{\mathrm{d}}$ & $\mathrm{K}_{\mathrm{oc}}$ & $\mathrm{K}_{\mathrm{c}}$ \\
\hline Alluvial & 1.006 & 0.653 & 0.24 & 437.4 & 5.29 & 1.586 & 0.655 & 0.37 & 386.8 & 8.35 \\
Sandy loam & 1.274 & 0.685 & 0.34 & 271.1 & 7.00 & 2.483 & 0.570 & 0.41 & 435.6 & 13.64 \\
Black & 2.061 & 0.606 & 0.40 & 361.6 & 8.45 & 4.205 & 0.479 & 0.48 & 646.9 & 17.23 \\
\hline
\end{tabular}

results have been reported for thiram adsorption into solid humic substance or soils ${ }^{26}$.

Distribution coefficient $\left(\mathrm{K}_{\mathrm{d}}\right)$ is a measure of soil adsorption capacity because it represents the relationship between the concentration of thiram in the solid (soils) and in the liquid (soil solution) for a given equilibrium concentration. The distribution coefficient $\left(\mathrm{K}_{\mathrm{d}}\right)$ of thiram in natural soil was the lowest (0.24) for alluvial soil. While it was the highest $(0.48)$ for farm yard manure treated in black soil Table-3. The higher $\mathrm{K}_{\mathrm{d}}$ values of black soil followed by sandy loam and alluvial soil again confirm the above order of adsorption ${ }^{27}$. Mandal and Adhikari ${ }^{12}$ established that the correlation between $K_{d}$ values and soil properties that the adsorption of pesticide are significantly related to organic carbon. Distribution coefficients $\left(\mathrm{K}_{\mathrm{d}}\right)$ of the thiram adjusted for soil organic carbon $\left(\mathrm{K}_{\mathrm{oc}}\right)$ and Freundlich parameters were closely related with organic matter. The adsorption constants normalized to organic carbon $\left(\mathrm{K}_{\mathrm{oc}}\right)$ and clay $\left(\mathrm{K}_{\mathrm{c}}\right)$ for soils in Table-3. Alluvial soil had maximum $\mathrm{K}_{\mathrm{oc}}$ values, while $\mathrm{K}_{\mathrm{c}}$ value was maximum in black and minimum in alluvial soils. Thus the organic matter is the most important factor in adsorption of thiram. Fushiwaki and Urano ${ }^{28}$ worked with ten pesticides and found that the amount of pesticide adsorbed on soils to be related to the organic carbon content of soils. However, adsorption of thiram is moderately high on the clay mineral also, probably because of the polar character of fungicide. Similar result has been reported that in general pesticide relates inversely to pesticide solubility in water ${ }^{29,30}$ and highly soluble pesticides are weakly adsorbed and pose a greater threat of ground water. The free energy $(\Delta \mathrm{G})$ of thiram have negative values (Table-2) and thus indicate that the adsorption is an exothermic process. Negative $\Delta \mathrm{G}$ values indicate the spontaneity of the adsorption process. Further low value of $\Delta \mathrm{G}$ revealed more or less physical nature of adsorption on the soil organic matter surface ${ }^{31}$. Mandal and Adhikari ${ }^{12}$ reported that the pesticide adsorption is temperature dependent and is exothermic in nature in different soil. In black soil the adsorption of thiram and its parameters were high because of high carbon content $(0.59 \%)$ in the soil. The studies reveal that thiram is strongly adsorbed on the black soil. The strong adsorption may be responsible for higher carbon content. Sorption increased with soil organic matter content but was not significantly correlated with other soil properties. By normalizing the Freundlich coefficient $(\mathrm{K})$ to organic matter content, the variability in obtained sorption coefficient $\left(\mathrm{K}_{\mathrm{oc}}\right)$ was substantially reduced. These results indicate that soil organic matter was the primary sorptive medium for thiram.

The addition of farm yard manure (FYM) at $0.25,0.5$ and $1 \%$ has increased the degradation of thiram in all the soils. It is clear that the addition of organic matter to the soils decreased the persistence of thiram. The greater the amount of organic matter, the greater is the decomposition of thiram leading to lesser persistence. Thus organic matter promoted the decomposition of thiram (Fig. 5). The black soil which is rich in organic matter content, showed appreciable decrease in persistence of thiram. During first three days, the higher concentration of organic matter i.e., 1 and $0.5 \%$ showed maximum degradation of thiram. While at lowest concentration $(0.25 \%)$ of organic matter persisted appreciably. The persistence of thiram has been found in the order alluvial soil $>$ sandy loam soil $>$ black soil. This order is inversely related to the adsorption of thiram by these soils. It has been reported that the fungicides do not persist in soil for a long time ${ }^{32}$. Since, the degradation of thiram was found to mainly microbial so the addition of the easily degradable organic substance resulted in spontaneous increase in microbiological activity and one would expect enhanced disappearance by such treatments. The addition of organic amendments showed primary effect and increased the disappearance of thiram.

Alluvial Soil

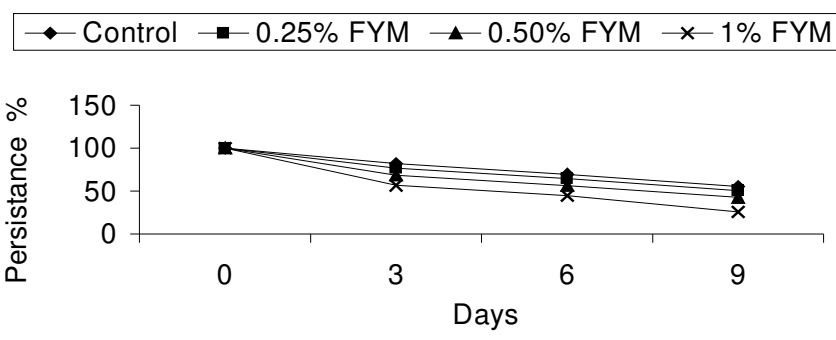

Sany Loam Soil

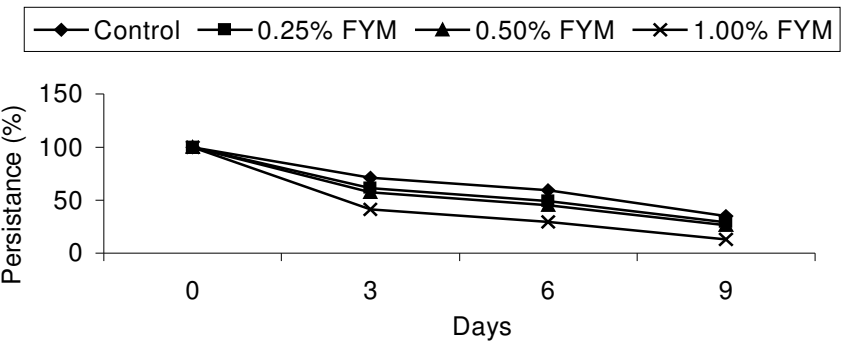

Black Soil

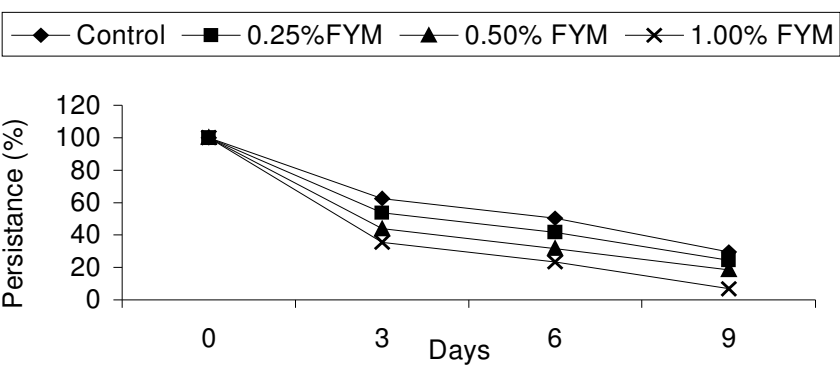

Fig. 5. Effect of organic matter (FYM) on the persistence of thiram 


\begin{tabular}{|c|c|c|c|c|c|c|}
\hline \multicolumn{7}{|c|}{$\begin{array}{c}\text { TABLE-4 } \\
\text { DETERMINATION COEFFICIENT }\left(\mathrm{R}^{2}\right) \text {, REGRESSION EQUATION, RATE CONSTANT AND } \\
\text { HALF-LIFE OF THIRAM IN PRESENCE OF ORGANIC MATTER (FYM) }\end{array}$} \\
\hline \multirow{2}{*}{$\begin{array}{c}\text { Organic } \\
\text { matter } \\
(\mathrm{FYM}) \\
\end{array}$} & \multicolumn{3}{|c|}{ Rate constant $\mathrm{K}\left(\mathrm{day}^{-1}\right)$} & \multicolumn{3}{|c|}{ Half life $T_{1 / 2}$ (Days) } \\
\hline & Alluvial soil & Sandy loam soil & Black soil & Alluvial soil & $\begin{array}{l}\text { Sandy } \\
\text { loam soil }\end{array}$ & Black soil \\
\hline Control & $\begin{array}{c}0.0651 \\
(\mathrm{Y}=2.002-0.0283 \mathrm{X})\end{array}$ & $\begin{array}{c}0.1176 \\
(\mathrm{Y}=2.031-0.0510 \mathrm{X})\end{array}$ & $\begin{array}{c}0.1261 \\
(\mathrm{Y}=1.982-0.0547 \mathrm{X})\end{array}$ & $\begin{array}{c}10.63 \\
(0.9805)\end{array}$ & $\begin{array}{c}5.890 \\
(0.9305)\end{array}$ & $\begin{array}{c}5.499 \\
(0.9420)\end{array}$ \\
\hline $0.25 \%$ & $\begin{array}{c}0.0693 \\
(\mathrm{Y}=1.980-0.03011 \mathrm{X})\end{array}$ & $\begin{array}{c}0.1244 \\
(\mathrm{Y}=1.972-0.0541 \mathrm{X})\end{array}$ & $\begin{array}{c}0.1305 \\
(\mathrm{Y}=1.918-0.0566 \mathrm{X})\end{array}$ & $\begin{array}{c}10.00 \\
(0.9895)\end{array}$ & $\begin{array}{c}5.568 \\
(0.9464)\end{array}$ & $\begin{array}{c}5.309 \\
(0.9615)\end{array}$ \\
\hline $0.50 \%$ & $\begin{array}{c}0.0789 \\
(\mathrm{Y}=1.943-0.0342 \mathrm{X})\end{array}$ & $\begin{array}{c}0.1304 \\
(\mathrm{Y}=1.9503-0.0566 \mathrm{X})\end{array}$ & $\begin{array}{c}0.1424 \\
(\mathrm{Y}=1.841-0.0618 \mathrm{X})\end{array}$ & $\begin{array}{c}8.783 \\
(0.9895)\end{array}$ & $\begin{array}{c}5.312 \\
(0.9508)\end{array}$ & $\begin{array}{c}4.867 \\
(0.9810)\end{array}$ \\
\hline $1.00 \%$ & $\begin{array}{c}0.1325 \\
(\mathrm{Y}=1.949-0.0575 \mathrm{X})\end{array}$ & $\begin{array}{c}0.1927 \\
(\mathrm{Y}=1.9043-0.0836 \mathrm{X})\end{array}$ & $\begin{array}{c}0.2751 \\
(\mathrm{Y}=1.966-0.1194 \mathrm{X})\end{array}$ & $\begin{array}{c}5.228 \\
(0.9502)\end{array}$ & $\begin{array}{l}3.5971 \\
(0.9467)\end{array}$ & $\begin{array}{c}2.519 \\
(0.9250)\end{array}$ \\
\hline
\end{tabular}

It has been reported that most pesticide in the soil breaks down or degrade overtime as a result of several chemical and microbiological reaction ${ }^{24}$. Organic matter is the seat of microbial activity and therefore, helps in the degradation of toxicants by furnishing higher number of microorganisms capable of degrading the fungicide ${ }^{33}$. Addition of organic matter, in general, results the increase of microbial activity of soil which adversely affects the biological degradation of the fungicide and an overall degradation of fungicide increases in soils with organic matter (farm yard manure). The kinetics of degradation of thiram (Table-4) in soils indicated that thiram had prolonged persistence in all the soils.

The persistence data indicated a close correspondence to first order kinetics $\left(r^{2}>0.92\right)$. The rate constant and half life value were derived by linear regression analysis of residual concentration on a logarithmic scale against time of incubation for each soil. Table- 4 reveals that the higher rate constant is 0.2751 day- 1 in black soil with $1.00 \%$ farm yard manure, while the half-life $\left(\mathrm{T}_{1 / 2}\right)$ value is maximum in alluvial soil 10.63/ day $^{34}$. It has also been reported that half-life values are inversely proportional to the rate constant $\left(\mathrm{K}_{\mathrm{deg}}\right)$ values ${ }^{35}$. Thus thiram is of low to moderate persistence. It was observed that thiram degrades more rapidly in acidic soils and in soil high in organic matter $^{36}$. In soil, thiram degrades by microbial action or by hydrolysis under acidic condition and it persist for longer in soil when localized in high concentration than when uniformly distributed through soil ${ }^{37}$. It can be concluded that the adsorption of thiram in soils is influenced by organic carbon content. The influence of texture or clay content of the soils is also a crucial factor. The degradation of thiram in soils is predominantly biological as well as chemical in nature. Lower persistence of thiram in the soil is due to rapid rate of degradation at smaller half-life values. Among soils, soil types do not influence the degradation of thiram.

\section{REFERENCES}

1. J.S. Aulakh, V.K. Sharma, R.K. Mahajan and A.K. Malik, Elect. J. Environ. Agric. Food Chem., 3, 751 (2004).

2. G.K. Kishore and S. Pande, Plant Disease, 91, 375 (2007).

3. D. Adamczyk, Environ. Eng. Sci., 23, 610 (2006).

4. M.S. Andrades, M.J. Sanchez-Martin and M.S. Camazano, J. Agric. Food Chem., 49, 2363 (2001)

5. M. Gavrilescu, Eng. Life Sci., 5, 497 (2005).

6. M.M. Arias, E. Paradelo and J. Lopez, J. Agric. Food Chem., 54, 8155 (2006).
7. G. Sheng, Y. Yang, M. Huang and K. Yang, Environ. Pollut., 134, 457 (2005).

8. C.L. Arora, Fundamental of Soil Science, Indian Society of Soil Science, IARI, New Delhi, India, p. 405 (2002).

9. L.C.F. Graham, IPM General Pesticide Information, Albama Pest Management Handbook, 1, 26 (2007).

10. J.R. Rangaswamy, P. Poornima and S.K. Majumdar, J. Assoc. Official Anal. Chem., 53, 519 (1970).

11. R.E. Green and V.K. Yamane, Soil Science: American Proceeding, 34, 353 (1970).

12. A.K. Mandal and M. Adhikari, J. Indian Soc. Soil Sci., 43, 561 (1995).

13. C.A.I. Goring and J.W. Hamaker, Organic Chemicals in Soil Environment, Marcel Dekkar, New York, Vol. 1, p. 49 (1972).

14. H.H. Cheng, Pesticides in the Soil Environment Process, Impact and Modeling, Soil Science Society of America, Madison, Vol. 2, p. 327 (1990).

15. S. Gupta, V.T. Gajbhiye and H.P. Agnihotri, Bull. Environ. Contamin. Toxicol., 66, 9 (2001).

16. A. Valverde-Garcia, E. Gonzalez-Prades, M. Villafranca Sanchez, F. DelreyBueno and A. Garcia-Rodriguez, Soil Sci. Soc. Am. J., 52, 1571 (1988).

17. O.M.S. Filipe, M.M. Vidal, A.C. Duarte and E.B.H. Santos, J. Agric. Food Chem., 57, 4906 (2009).

18. C.H. Giles, T.H. MacEvan, S.N. Nakhwa and D. Smith, J. Chem. Soc., 111, 3973 (1960).

19. N. Singh, J. Agric. Food Chem., 50, 6434 (2002).

20. N. Priyantha, A. Navaratne, C.B. Ekanayake and A. Ratnayake, J. Environ. Sci. Tech., 5, 547 (2008).

21. I. Sahid, W. Razlin and W. Zabbar, Bull. Environ. Contamin. Toxicol., 51, 605 (1993).

22. D.K. Sharma, B.C. Verma, S. Sood, N. Verma and K.C. Sood, Pesti. Res. J., 12, 1 (2000).

23. D.A Martens and J.M. Bremner, Pesti. Sci., 49, 344 (1997).

24. A.S. Chowdhury, M. Pradhan and N. Saha, Indian J. Microbiol., 48, 114 (2008).

25. D. Sharma and M.D. Awasthi, Plant Soil, 195, 293 (1997).

26. O.M.S. Filipe, M.M. Vidal, A.C. Duarte and E.B.H. Santos, Talanta, 72, 1235 (2007).

27. R.L. Celis, M.C. Cox and J. Hermonsin, J. Environ. Qual., 26, 472 (1997).

28. Y. Fushiwaki and K. Urano, J. Health Sci., 47, 429 (2001).

29. R.N. Pandey and A.K. Agnihotri, J. Indian Soc. Soil Sci., 43, 451 (2000).

30. R.L. Mahler, H.W. Homan and G.P. Carpenter, Pesticide and Their Movement in Soil and Water, Quality Water for Idaho Current Information, University of Idaho Moscow, S. No. 865, 1 (2002).

31. T.H. Hanumantharaju and M.D. Awasthi, Pesti. Res. J., 14, 292 (2002).

32. A.K. Ahuja and B.N. Pande, Pesti. Res. J., 17, 74 (2005).

33. M.S. Digrak and S. Ozcelik, Bull. Environ. Contamin. Toxicol., 60, 916 (1998).

34. M.S. Chatrath and T.N. Raju, Indian Phytopathol., 39, 312 (1986).

35. T.H. Hanumantharaju and M.P. Awasthi, J. Ind. Soc. Soil Sci., 51, 528 (2003).

36. V.K. Sharma, J.S. Aulakh and A.K. Malik, J. Environ. Monit., 5, 717 (2003).

37. R.L. Griffith and J.R. Matthews, Ann. Appl. Biol., 64, 113 (2009). 